1. MBBS

Undergraduate Student Medicine Nishtar Medical University, Multan Pakistan.

2. MBBS

Undergraduate Student of Medicine Nishtar Medical University, Multan, Pakistan.

3. MBBS

House Officer Medicine Nishtar Medical University, Multan, Pakistan.

4. MBBS

Undergraduate Student of Medicine Nishtar Medical University, Multan, Pakistan.

5. MBBS

Undergraduate Student of Medicine Nishtar Medical University, Multan, Pakistan.

6. MBBS

Undergraduate Student of Medicine Nishtar Medical University, Multan, Pakistan.

7. MBBS

Undergraduate Student of Medicine Nishtar Medical University, Multan, Pakistan.

Correspondence Address:

Dr. Waseem Sajjad

Department of Medicine

Nishtar Medical University, Multan,

Pakistan.

mwsdouna@gmail.com

Article received on:

19/10/2020

Accepted for publication:

29/06/2021

\section{Prevalence of depression among medical students: A Cross- Sectional Study.}

\author{
Waseem Sajjad", Anwisha Samreen², Syed Asfand Yar Shah ${ }^{3}$, Afifa Batool ${ }^{4}$, Muhammad Umair ${ }^{5}$, \\ Talha Ahmad ${ }^{6}$, Zainul Abideen
}

ABSTRACT... Objectives: To determine the prevalence of depression among medical students and its association with various sociodemographic characteristics. Study Design: Cross-Sectional Study. Setting: Nishtar Medical University, Multan. Period: August 2019 to September 2020. Material \& Methods: A sample of 315 medical students were chosen by stratified random sampling technique. Patient Health Questionnaire 9 (PHQ-9) was used for screening and assessing the severity of depression. A special questionnaire was designed containing sociodemographic and educational characteristics. Data were collected via online forms and were analyzed using SPSS V26. Results: Out of 315 students, who participated in the study, 134 (42.5\%) were female students, and 181 (57.5\%) were male students. 63 (20\%) students were taken from each academic year from 1st year through 5 th year (final year). $64 \%$ of the students were suffering from depression. The proportion of students suffering from mild, moderate, moderately severe, and severe depression was 27\%, 18\%, 11\%, and $8 \%$ respectively. Depression was more prevalent among female students (73.1\%) as compared to male students (58.0\%) with a p-value <0.05. Conclusion: Depression is a serious problem for medical students. It was significant among female, preclinical students, living in the home with a family history of depression in financial pressure. It should be sorted out early to make early interventions.

Key words: Cross-Sectional Study, Depression, Medical Students, Multan, Nishtar Medical University, Prevalence, PHQ-9.

Article Citation: Sajjad W, Samreen A, Shah SAY, Batool A, Umair M, Ahmad T, Zain ul Abideen. Prevalence of depression among medical students: A CrossSectional Study. Professional Med J 2021; 28(12):1723-1731. https://doi.org/10.29309/TPMJ/2021.28.12.6164

\section{INTRODUCTION}

Depressive disorders are characterized by sadness, loss of interest or pleasure, feelings of guilt or low self-worth, disturbed sleep or appetite, feelings of tiredness, and poor concentration. ${ }^{1}$ Globally, it was estimated that the total number of people with depression exceeded 300 million, equivalent to $4.4 \%$ of the world population in 2015 and it will account for any physical or mental disorder in the world at the highest level of disability by 2030. Depression is also the major contributor to suicide deaths, nearly 800,000 annually. ${ }^{1}$ A recent meta-analysis of 195 studies from 47 countries highlighted that $27 \%$ of respondents to medical students screened positive for depression or depressive symptoms and $11 \%$ reported suicidal ideation. ${ }^{2}$ These estimates are two to five times higher than those reported in the general population. ${ }^{3}$

Studies have found that $45.5 \%$ of Pakistani medical students suffer from depression. ${ }^{4}$ The prevalence of depression among medical students was $39.6 \%, 75 \%, 75.5 \%$, and $92 \%$ in Islamabad, Lahore, Sargodha, and Karachi respectively. ${ }^{5-8}$ University students are a special group of people who endure a critical transitory period during which they go from adolescence to adulthood and maybe one of the most stressful times in a person's life. ${ }^{9}$ Childhood adversity such as deprivation, neglect, mental abuse, physical abuse, sexual abuse, and sibling's unequal parental treatment may contribute to adult depression. ${ }^{10}$ High levels of the psychological problem among medical students are most likely due to the academic, political, and social demands 
put on students by college environments at a time when they are also involved in lifestyle and career issues. ${ }^{11}$ The potential consequences of depression on medical students include disruption in classroom functioning and patient care environments that would adversely impact on community health. ${ }^{12}$ For their counseling and rehabilitation, therefore, there is a need to quantify the anxiety, depression, and its associated factors among medical students.

The objective of this study was to determine the prevalence of depression among medical students of Nishtar Medical University, Multan, Pakistan. The study also aimed to explore the association between depression and certain factors such as gender, age, class, family history of psychiatric illnesses, residence, and socioeconomic status.

\section{MATERIAL \& METHODS}

This Cross-Sectional Study was conducted at Nishtar Medical University, Multan, Pakistan. From August 2019 to September 2020. The study was reviewed and approved by Ethical Review Board. The sample size was 315 . The sample size was calculate using OpenEpi ${ }^{\circledR}$ with $95 \%$ confidence and $5 \%$ error of margin. The Sampling Technique was Stratified random sampling.

Only the $1^{\text {st }}$ year to $5^{\text {th }}$ year MBBS students of Nishtar Medical University Multan were included in the study. BDS, nursing, and paramedical students were not included.

Data was collected by an online survey. The form link was sent to the individual student of various classes. Only 63(20\%) students were taken from each academic year from 1st year through 5th year (final year). Dually filled and incompletely filled forms were rejected. Patient Health Questionnaire 9 (PHQ-9) was used for screening and assessing the severity of depression. PHQ-9 has a sensitivity of $88 \%$ and a specificity of $88 \%$ for major depression when the cut-off score of 10 is taken. ${ }^{13}$ Some sociodemographic questions include age, gender, academic year, monthly family income, residence, and family history of psychiatric disorders. Following criteria was followed for assessing the severity of depression
(Table-I).

\begin{tabular}{|l|c|c|}
\hline $\begin{array}{c}\text { Total } \\
\text { Score }\end{array}$ & Depression Severity & Group \\
\hline $0-4$ & No/Minimal depression & $\begin{array}{c}\text { Depression } \\
\text { Absent }\end{array}$ \\
\hline $5-9$ & Mild depression & $\begin{array}{c}\text { Depression } \\
\text { Present }\end{array}$ \\
\hline $10-14$ & Moderate depression & \multirow{2}{|c|}{} \\
\hline $15-19$ & Moderately severe depression & \\
\hline $20-27$ & $\begin{array}{r}\text { Severe depression } \\
\text { Table-I. Interpretation of Total Score. }\end{array}$ \\
\hline
\end{tabular}

Data were analyzed by using Statistical Package for Social Sciences (SPSS V26) ${ }^{\circledR}$, and Microsoft Excel $365 \AA$ for making graphs and tables. Frequencies and percentages were calculated for qualitative variables. The mean and the standard deviation were calculated for quantitative data. Chi-square test was used for comparing the different variables to calculate the $p$-value. A p-value of equal to or less than 0.05 was considered statistically significant. To calculate the odds ratio and 95\% confidence interval, each variable was divided into two groups. i.e Gender into male and female students, Age into 17-20 year and 21-25 years, an academic year into pre-clinical (that includes 1st year and 2nd year students) and clinical (that includes 3rd year, 4th year and 5th year students), residence into living in-home or hostel, family history into present or absent.

\section{RESULTS}

About 358 students filled the form, after removing incompletely or dually filled forms, 315 remained, so the response rate is $87.98 \%$. Out of 315 students, 134 (42.5\%) were female students, and 181 (57.5\%) were male students. 63 (20\%) students were taken from each academic year from 1st year through 5th year (final year). The mean age in years was found to be 21.19 with a standard deviation of 1.7.

187 (59.4\%) students were residing in the hostel and $128(40.6 \%)$ were living with their family in homes. Sixty four (20.3\%) students had a monthly family income of less than 50000 PKR, and $139(44.1 \%)$ students had in between 50000 to 100000 PKR, and 112 (35.6\%) students had 
above 100000 PKR. Out of 315 students, 252 (80\%) had no family history of psychiatric illnesses while others 64 (20\%) had family history present. Most of the students were suffering from mild depression and least were suffering from severe depression as shown in Figure-1.

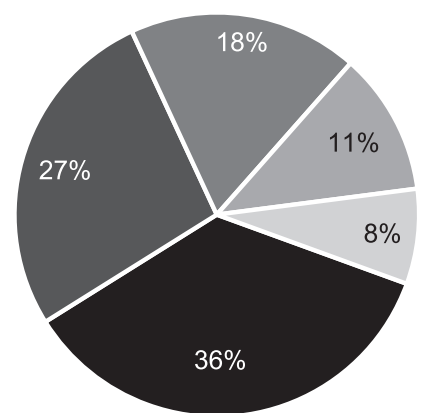

No/Minimal

Mild Moderate $\square$ Moderately Severe $\square$ Severe

Figure-1. Proportion of students suffering from various severity of depression.

$64 \%$ of the students were provisionally diagnosed as depressed (PHQ score $>4$ ). While $37 \%$ of the students were suffering from major depressive disorders (PHQ score $\geq 10$ ). Depression was more prevalent among female students as compared to their male fellow students (Figure-2).

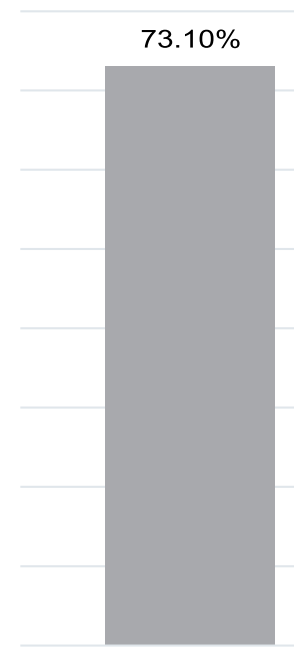

Female

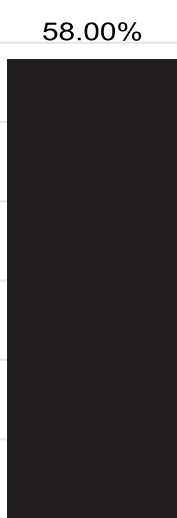

Male
Figure-2. Gender comparison for the severity of depression.

The relationship between sociodemographic characteristics and the severity of depression is shown in Table-Il.
Our study shows that there was no or minimal depression among male (42\%), 5th year (54.0\%) 24 years old (60\%), hostel residents (36.4\%), with a family income of 50000 to 100000 (39.6\%) and with no family history of psychiatric illnesses (37.7\%) (Table-I). Though the relationship between family history of psychiatric illnesses and depression was not significant ( $p$-value $>0.05$ ), yet those female students who had positive family history had a significantly high prevalence (81.8\%) as compared to those female students who had a negative family history $(70.3 \%)$ with a p-value of 0.047 . In between male students, family history was not significant ( $p$-value $=0.832$ ).

The inter-class comparison shows that the severity of depression decreased gradually from 1st year through the final year ( $p$-value $=0.017$ ), as shown by the purple dotted line in Figure-3. It also shows that depression was highest among 2nd-year female students (86.1\%) as compared to female students of the rest of the classes but it was not significant ( $p$-value $=0.466)$. But the difference was significant $(p$-value $=0.008)$ in the case of male students of various classes, depression being highest among 1st-year male students (78.4\%).

The intra-class comparison shows that more female students were depressed as compared to their male fellow students except in the case of 3rd year, where male students $(61.0 \%)$ were more depressed as compared to their female fellows $(54.5 \%)$. Within the class, most of the students were not depressed or minimally depressed and least were severely depressed except in the 1st year and 2nd year, in which most of the students were mildly depressed (Figure-3).

There was no significant difference in the severity of depression within 1st year, 2nd year, 3rd year, and 4th year with a p-value of $0.817,0.127,0.621$, 0.222 respectively. But in the case of the final year, it was significant $(p-v a l u e=0.009)$.

The odds ratio and 95\% confidence interval for various socio-demographic characteristics are shown in Table-III. 


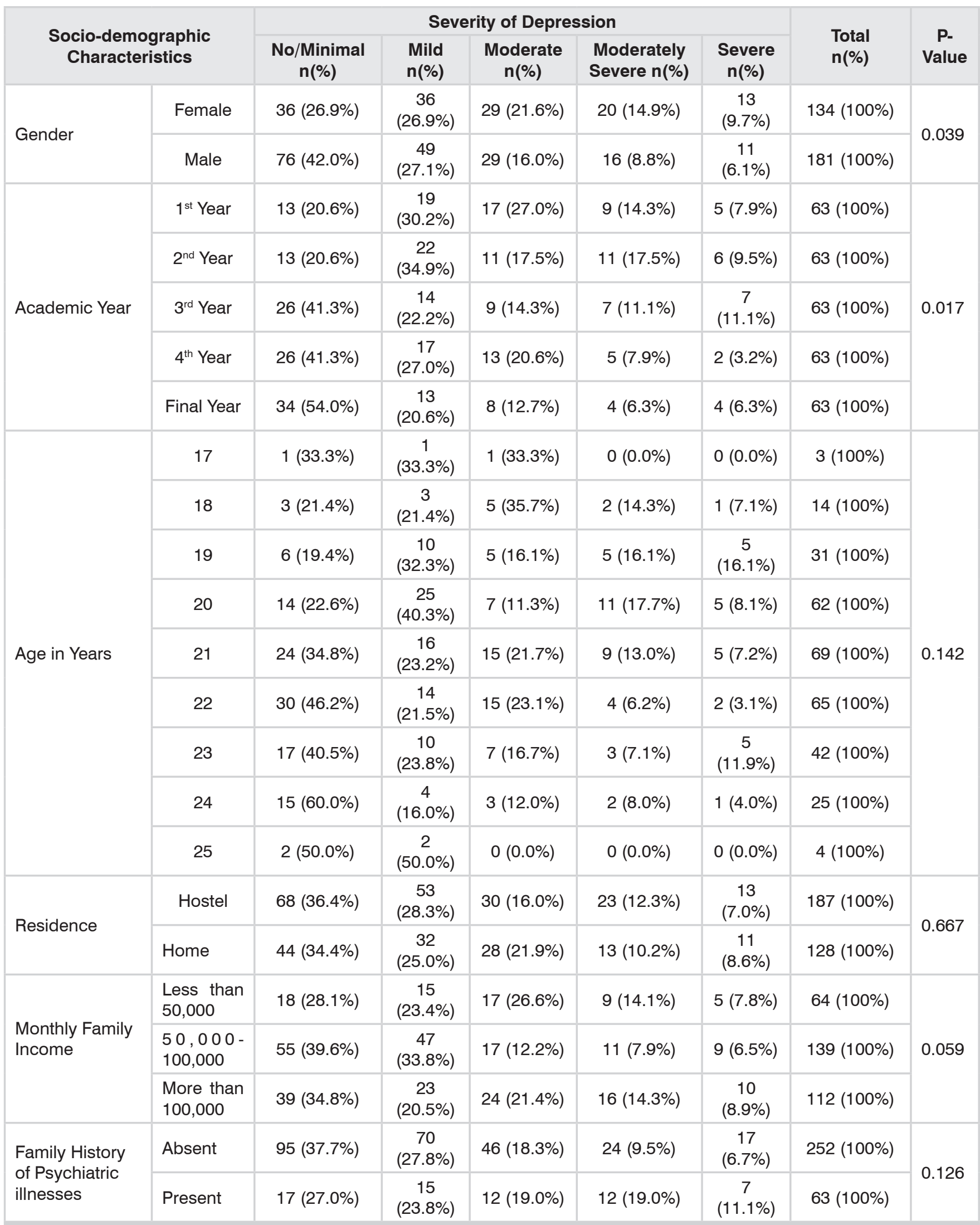

Table-II. Relationship between sociodemographic characteristics and the severity of depression $(n=315)$. 


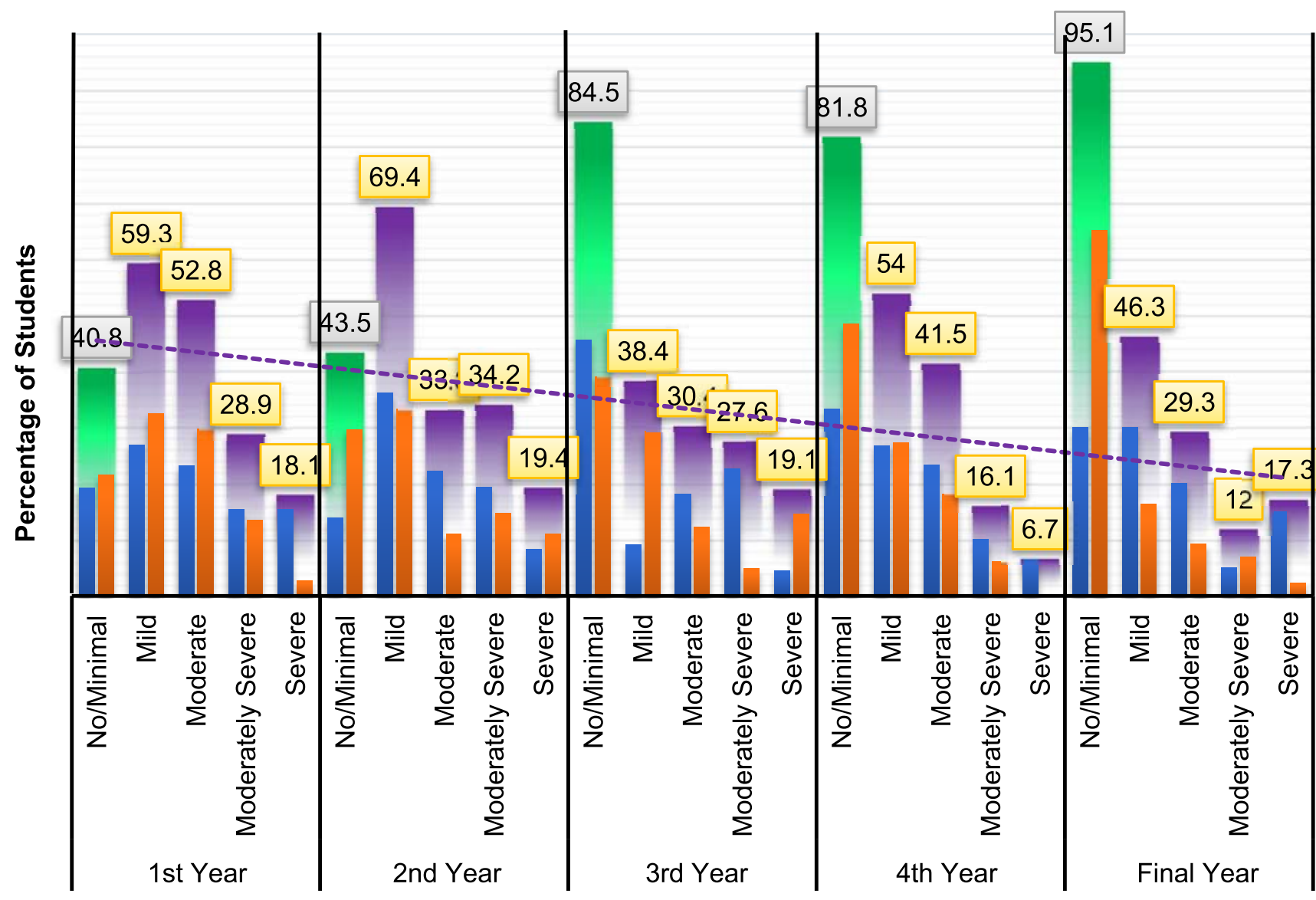

Depression Absent

Depression Present

Female

Male

Linear (Depression Present)

Figure-3. Inter-Class and Intra-Class comparison for the severity of depression among male and female students. (The purple and the green bars show the cumulative percentages).

\begin{tabular}{|c|c|c|c|c|c|c|c|c|}
\hline \multirow{2}{*}{\multicolumn{2}{|c|}{$\begin{array}{l}\text { Socio-Demographic } \\
\text { Characteristics }\end{array}$}} & \multicolumn{2}{|c|}{ Depression } & \multirow{2}{*}{$\begin{array}{l}\text { Total } \\
\mathrm{n}(\%)\end{array}$} & \multirow{4}{*}{$\begin{array}{l}\text { Odds } \\
\text { Ratio }\end{array}$} & \multicolumn{2}{|c|}{$\begin{array}{c}\text { 95\% Confidence } \\
\text { Interval }\end{array}$} & \multirow{4}{*}{$\begin{array}{r}\text { P-Value } \\
0.006\end{array}$} \\
\hline & & \multirow{2}{*}{$\begin{array}{c}\begin{array}{c}\text { Absent } \\
\text { n (\%) }\end{array} \\
36(26.9 \%)\end{array}$} & \multirow{2}{*}{$\begin{array}{c}\begin{array}{c}\text { Present } \\
\text { n(\%) }\end{array} \\
98(73.1 \%)\end{array}$} & & & Lower & Upper & \\
\hline \multirow{2}{*}{ Gender } & Female & & & $134(100 \%)$ & & & & \\
\hline & Male & 76 (42.0\%) & 105 (58.0\%) & $181(100 \%)$ & & 0.313 & $0.8<2$ & \\
\hline \multirow{2}{*}{ Residence } & Hostel & 68 (36.4\%) & 119 (63.6\%) & 187 (100\%) & \multirow{2}{*}{1.091} & \multirow{2}{*}{0.681} & \multirow{2}{*}{1.747} & \multirow{2}{*}{0.717} \\
\hline & Home & 44 (34.4\%) & $84(65.6 \%)$ & $128(100 \%)$ & & & & \\
\hline \multirow{2}{*}{$\begin{array}{l}\text { Family History } \\
\text { of Psychiatric } \\
\text { illnesses }\end{array}$} & Absent & 95 (37.7\%) & 157 (62.3\%) & $252(100 \%)$ & \multirow{2}{*}{1.637} & \multirow{2}{*}{0.888} & \multirow{2}{*}{3.019} & \multirow{2}{*}{0.112} \\
\hline & Present & $17(27.0 \%)$ & 46 (73.0\%) & $63(100 \%)$ & & & & \\
\hline \multirow{2}{*}{ Academic Year } & Pre-Clinical & $26(20.6 \%)$ & $100(79.4 \%)$ & 126 (100\%) & \multirow{2}{*}{0.311} & \multirow{2}{*}{0.186} & \multirow{2}{*}{0.523} & \multirow{2}{*}{0.001} \\
\hline & Clinical & 86 (45.5\%) & $103(54.5 \%)$ & 189 (100\%) & & & & \\
\hline \multirow{2}{*}{$\begin{array}{l}\text { Age Groups in } \\
\text { years }\end{array}$} & $17-20$ & $24(21.6 \%)$ & 87 (78.4\%) & $111(100 \%)$ & \multirow{2}{*}{0.364} & \multirow{2}{*}{0.214} & \multirow{2}{*}{0.618} & \multirow{2}{*}{0.001} \\
\hline & $21-25$ & $88(43.1 \%)$ & 116 (56.9\%) & 204 (100\%) & & & & \\
\hline
\end{tabular}




\section{DISCUSSION}

Depression is a grave psychological problem. It badly affects the social life of students. Medical students are future assets of a country, if they are physically and mentally healthy and strong, they strive more effectively for the better health of society. But unfortunately, they are more depressed as compared to the general population. A meta-analysis showed that approximately one-third of medical students worldwide suffer from depression, and an overall prevalence of depressive symptoms among medical students is higher than that reported in the general population. $^{2}$

Our study showed that the prevalence of depression among medical students is $64 \%$, out of which $27 \%$ of the students had mild depression, $18 \%$ had moderate, $11 \%$ had moderately severe and $8 \%$ had severe depression. The results are slightly higher than the other study conducted at the same institute, which showed a 51.5\% prevalence. ${ }^{14}$ This increased prevalence in our study may be because of a recent change in the study curriculum. Other studies conducted among medical students in Pakistan reported the following prevalence, Shifa College of Medicine Islamabad $(39.6 \%)^{5}$, Lahore Medical and Dental College (75\%, out of which $39.2 \%$ had mild depression, $22.3 \%$ had moderate, $12 \%$ had moderate to severe, and $1.5 \%$ had severe depression) ${ }^{6}$, Multi centered study in Karachi $(92 \%)^{15}$ and Sargodha Medical College, Sargodha $(75.5 \%) .^{8}$ This difference in prevalence may be due to different study environments, different teaching methodologies, and peer support. While studies conducted outside Pakistan reported the following prevalence: Ireland $(39 \%)^{16}$, Cameroon $(65.2 \%$ students were provisionally diagnosed with depression. Out of which, $34.6 \%$ had mild, $26.4 \%$ had moderate, $3.4 \%$ had moderately severe and $0.80 \%$ had severe depression) ${ }^{12}$, Brazil $(34.6 \%)^{17}$, Saudi Arabia $(83.4 \%)^{18}$, India $(44.42 \%)^{19}$, Egypt $(60.8 \%) .^{20}$ This variation in prevalence may be due to geographical variations and differences in the social, political, and educational environment. Slight variations in prevalence may be due to the different tools and methodologies used for screening of depression.
On contrary to a former study conducted at the same institute which reported a high prevalence among males $(61.9 \%)$ as compared to female students $(45 \%)^{14}$, we found that more female students were depressed $(73.1 \%)$ as compared to male students (58.0\%). The reason might be their smaller sample size and different sampling technique. Our study is supported by other studies conducted in Pakistan ${ }^{5,6,8}$ and abroad which reported that more female students were suffering from depression as compared to male students, as in Serbia (female 53\%, male 38\%) ${ }^{21}$, India (female $76 \%$, male $65 \%$ ) ${ }^{19}$, Saudi Arabia (female $87.6 \%$, male $66.6 \%$ ). ${ }^{18}$ This is because female students are hardworking and more ambitious towards their studies with a sense of competition. Their coping strategies are less efficient, and they are not much exposed to the outdoor environment and recreational activities as compared to males. Moreover, male students usually have a large social support system.

In the current study, the Prevalence of depression decreased gradually with increasing academic year, 1st year (79.4\%), 2nd year $(79.4 \%)$, 3rd year $(58.7 \%)$, 4th year $(58.7 \%)$, and final year (45.9\%). Moreover, the pre-clinical students had a high prevalence $(79.4 \%)$ as compared to clinical students $(54.5 \%)$. Alharbi et al found similar results in his study. ${ }^{18}$ Other studies also reported a high prevalence among 1st-year Medical students. $8,16,21,22$ This is because of the change in environment, the format of the syllabus, different teaching methodology, and teasing by senior students. A study conducted at the same institute by Samina et al showed that more final year students $(56.8 \%)$ are depressed as compared to 2 nd year (56.6\%) 3rd year (56.3\%) 1st year (53.3\%) and 4th year (29.5\%) respectively. ${ }^{14}$ Some studies reported high prevalence among clinical students, for example in Ireland (Preclinical: 36\% and Clinical: $41 \%)^{8}$ and Lahore Medical and Dental college (clinical $60.5 \%$ as compared to preclinical $39.5 \%) .{ }^{6}$ In our study, the least prevalence of depression among final year students might be due to the different learning environments, different teaching methodology and exam structure, easy clinical rotations, the interaction between teachers and senior students, and the 
sense of being free from hard studies after their last professional examination.

Our study reported that $78.4 \%$ of age group $17-20$ years ( 17 years old $=66.6 \%, 19$ years old $=78.5 \%$, 19 years old $=80.6 \%, 20$ years old $=77.4 \%$ ) were depressed as compared to $56.9 \%$ of age group $21-25$ years (21 years old $=65.2 \%$, 22 years old $=53.8 \%$, 23 years old $=59.5 \%$, 24 years old $=40 \%, 25$ years old $=50 \%$ ). So, depression was decreasing with increasing age as supported by and Zafar $U$ et al. ${ }^{6}$ The study by Uttra et al showed a high prevalence in the age group of 23 to 22 years and it decreased with increasing age. ${ }^{8}$ This is because of increased coping strategies learned with increasing age.

A study conducted at Mimer Medical College, Pune, India ${ }^{22}$ reported that the hostilities had less depression (70\%) as compared to localities (73\%). We found similar results in our study that the hostel residents were less depressed (63.6\%) as compared to those living at home with their families (65.6\%). But other studies conducted in Multan $^{14}$, Sargodha ${ }^{8}$, and Madinah ${ }^{23}$, reported a high prevalence among hostel residents. The reason is that social support is thought to be a protective factor against depression, whether it is provided by hostel residents or family members. Perhaps due to that student-friendly environment, freedom of accountability, and supportive relationship between hostel residents made them less depressed in our study. Moreover, students living in their homes are under constant supervision of their family which may make them depressed.

The present study showed that students with a moderate family income of 50000-100000 PKR had a low prevalence of depression (60.4\%) as compared to those with a low family income of less than 50000 PKR and high monthly family income of greater than 100000 PKR $(71.9 \%$ and $65.2 \%$ respectively). Other studies also reported that family income is protective against depression..$^{20,23}$ But a study concluded that financial pressure did not contribute to depression, suggesting that academic pressure and future worries being the most important stressors that contribute to depression. ${ }^{8}$ This may be because most of the institutions have financial support associations that help needy students, moreover, there are also some financial support programs by the government for students.

On contrary to a study high prevalence of depression in those with negative family history ${ }^{8}$, we found that the students with a positive family history were more depressed (73\%) as compared to those with a negative family history (62.3\%). Our results are corroborated with other studies ${ }^{7,24}$, as it is postulated that some genes might be involved in depression. ${ }^{25}$

There are certain limitations to our study. We collected data from MBBS students only, data from BDS students, nursing, and paramedical students were not collected. We could not assess the different stressors. It was conducted in a public sector college and its results may differ from private medical colleges. We could not find the data on the prevalence of depression in the general population and non-medical students of Pakistan so could not compare it with our results.

We suggest a longitudinal study to assess the effect of depression on the physical and mental health of students and its effect on their social life and academic performance. Further, the mental status of students should be assessed before and after entering medical college. The diagnosis of depression should be confirmed by interviews. Data should be collected about phases of the menstrual cycle in the case of female students. The effect of depression on drug abuse should also be considered.

\section{CONCLUSION}

Depression is a grave situation among medical students. It was significant among female, preclinical students, living in the home with a family history of depression in financial pressure. It should be sorted out early to make early interventions. Teachers should know about it and they should try to lessen various stressors for students. Students should be taught about various coping strategies and relaxation techniques. They should be provided with opportunities for 
various extracurricular activities. They should be encouraged to seek peer help whenever needed. They should make a strong social support system among their fellows and family members. As with a healthy mind, they would deal with their practical life more efficiently.

Copyright@ 29 June, 2021.

\section{REFERENCES}

1. World Health Organization. Depression and other common mental disorders: Global health estimates. World Health Organization 2017. https://apps.who.int/ iris/handle/10665/254610. License: CC BY-NC-SA 3.0 IGO.

2. Rotenstein LS, Ramos MA, Torre M, Segal JB, Peluso MJ, Guille C, Sen S, Mata DA. Prevalence of depression, depressive symptoms, and suicidal ideation among medical students: A systematic review and meta-analysis. Jama. 2016 Dec 6; 316(21):2214-36. doi:10.1001/jama. 2016.17324.

3. Cvejic E, Parker G, Harvey SB, Steel Z, HadziPavlovic D, Macnamara CL, Vollmer-Conna U. The health and well-being of Australia's future medical doctors: Protocol for a 5-year observational cohort study of medical trainees. BMJ open. 2017 Sep 1; 7(9):e016837. doi: 10.1136/bmjopen-2017-016837.

4. Hashmi AM, Aftab MA, Naqvi SH, Sajjad W, Mohsin M, Khawaja IS. Anxiety and depression in Pakistani medical students: A multicenter study. Health Med. 2014; 8(7):813-20. https://www.researchgate.net/ profile/Awais_Aftab/publication/264742173_Anxiety_ and_Depression_in_Pakistani_Medical_Students_A_ Multi-Center_Study/links/53f8dd580cf27925e2e0d515/ Anxiety-and-Depression-in-Pakistani-Medical-StudentsA-Multi-Center-Study.pdf.

5. Abrar A, Kazim M, Hanif M, Mansoor S, Tahir S, Makken $\mathrm{N}$, Yousufzai W. Prevalence of anxiety and depression among medical students of shifa college of medicine. Pakistan Journal of Neurological Sciences (PJNS). 2014; 9(3):12-5. https://ecommons.aku.edu/pjns/vol9/ iss $3 / 4 /$.

6. Zafar U, Daud S, Khalid A. Determinants of depression among undergraduate medical students of a private medical college in Lahore. JPMA. 2020 Jan 14; 2019. DOI: 10.5455/JPMA.13896.

7. Deepak P, Usmani UU, Washdev W, Mirza D, Das K, Rehman RU. Prevalence of depression and anxiety among undergraduate medical students in a government medical college of Karachi. Journal of Postgraduate Medical Institute (Peshawar-Pakistan). 2017 Aug 10; 31(3). https://jpmi.org.pk/index.php/jpmi/ article/view/2091.
8. Uttra AM, Uttra MG, Rauf A, Uttra MM, Hasan UH, Batool A. Prevalence of depression. The Professional Medical Journal. 2017 Mar 7; 24(03):482-9. DOI: 10.17957/ tpmj/17.3708.

9. Buchanan JL. Prevention of depression in the college student population: A review of the literature. Archives of Psychiatric Nursing. 2012 Feb 1; 26(1):2142. DOI: 10.1016/j.apnu.2011.03.003.

10. Heim C, Newport DJ, Mletzko T, Miller AH, Nemeroff CB. The link between childhood trauma and depression: Insights from HPA axis studies in humans. Psychoneuroendocrinology. 2008 Jul 1; 33(6):693-710. DOI: 10.1016/j.psyneuen.2008.03.008.

11. Jadoon NA, Yaqoob R, Raza A, Shehzad MA, Zeshan SC. Anxiety and depression among medical students: A cross-sectional study. JPMA. The Journal of the Pakistan Medical Association. 2010 Aug; 60(8):699702. https://jpma.org.pk/article-details/2243.

12. Ngasa SN, Sama CB, Dzekem BS, Nforchu KN, Tindong $M$, Aroke D, Dimala CA. Prevalence and factors associated with depression among medical students in Cameroon: A cross-sectional study. BMC psychiatry. 2017 Dec 1; 17(1):216. DOI: 10.1186/ s12888-017-1382-3.

13. Kroenke K, Spitzer RL. The PHQ-9: A new depression diagnostic and severity measure. Psychiatric annals. 2002 Sep 1; 32(9):509-15. https://doi.org/10.3928/00485713-20020901-06.

14. Samina R, Zainab W, Fatima S. Perceived stress among medical students: Prevalence, source and severity. Psychol Psychother Res Stud. 2(3).PPRS.000538.2019. DOI: 10.31031/PPRS.2019.02.000538.

15. Kumari U, Dawani N, Devnani J, Qureshi MF, Soleja FK, Mohammad D, Abubaker ZJ, Haroon A, Sadiq S. Depression among medical students of Karachi $A$ cross sectional study. MedEd Publish. 2019 Sep 18;8. DOI: https://doi.org/10.15694/mep.2019.000181.1.

16. Fitzpatrick O, Biesma R, Conroy RM, McGarvey A. Prevalence and relationship between burnout and depression in our future doctors: A crosssectional study in a cohort of preclinical and clinical medical students in Ireland. BMJ open. 2019 Apr 1; 9(4):e023297. DOI: 10.1136/bmjopen-2018-023297.

17. Moutinho IL, Maddalena ND, Roland RK, Lucchetti AL, Tibiriçá SH, Ezequiel OD, Lucchetti G. Depression, stress and anxiety in medical students: A crosssectional comparison between students from different semesters. Revista da Associação Médica Brasileira. 2017 Jan; 63(1):21-8. https://doi. org/10.1590/1806-9282.64.10.902. 
18. Alharbi H, Almalki A, Alabdan F, Haddad B. Depression among medical students in Saudi medical colleges: A cross-sectional study. Advances in Medical Education and Practice. 2018; 9:887. https://doi.org/10.2147/ AMEP.S182960.

19. Agrawal N, Sharma S, Meena R, Uppadhaya SK, Mittal M. Prevalence of depression and its associated factors among students of a Medical College in Western Rajasthan. Natl J Comm Med. 2017; 8(1):12-6. https:// www.bibliomed.org/mnsfulltext/159/159-1470316023. pdf?1602958000.

20. Yousif W, Wahed A, Hassan S. Alexandria University Faculty of Medicine Prevalence and associated factors of stress, anxiety and depression among medical Fayoum University students. Alexandria Journal of Medicine. 2017; 53(1):77-84.

21. Rančić N, Kocić $B$, Stević S, llić $M$, Stojanović $M$, Stojanović M. Prevalence of depressive symptoms in medical students. Acta Medica Medianae. 2019;58(4):18-25. https://scindeks.ceon.rs/article.aspx? artid=0365-44781904018R.
22. Patil K, Chande D, Pratinidhi SA, Bhat A. A Study to assess depression levels in MBBS students. Indian Journal of Mental Health. 2018; 5(3). DOI: 10.30877/ IJMH.5.3.2018.296-300.

23. Sultan SA, Alhosaini AA, Sheerah SA, Alrohaily AA, Saeed HM, Al-Raddadi NM, Halawani MS, Shaheen MA, Turkistani AY, Taha H, Alahmadi M. Prevalence of depression among medical students at Taibah University, Madinah, Saudi Arabia.

24. Al-Shahrani MS, Alharthi MH, Alamri MS, Ibrahim ME. Prevalence of depressive symptoms and its predicted factors among medical students in University of Bisha, Saudi Arabia. Int J Ment Health Syst. 2020 Mar 9;9:1-7.

25. Ledford $\mathrm{H}$. First robust genetic links to depression emerge. Nature. 2015 Jul 16; 523(7560):268-9. doi: 10.1038/523268a.

\begin{tabular}{|c|l|l|l|}
\hline \multicolumn{3}{|c|}{ AUTHORSHIP AND CONTRIBUTION DECLARATION } \\
\hline No. & Author(s) Full Name & \multicolumn{1}{|c|}{ Contribution to the paper } & Author(s) Signature \\
\hline 1 & Waseem Sajjad & $\begin{array}{l}\text { Concept and Study Design, Data } \\
\text { analysis and Manuscript writing. } \\
\text { Critical Revision of article. }\end{array}$ \\
\hline 3 & Anwisha Samreen & Syed Asfand Yar Shah & Critical Revision of article. \\
\hline 4 & Afifa Batool & Data collection. \\
\hline 6 & Talha Ahmad & Data collection. \\
\hline 7 & Zainul Abideen & Data collection. \\
\hline
\end{tabular}

